\title{
Some Generative Mechanisms of Intellectual
} Production

The three markets theory

\section{Mohamed Cherkaoui}

\section{OpenEdition}

\section{Journals}

Édition électronique

URL : http://journals.openedition.org/ress/873

DOI : $10.4000 /$ ress.873

ISSN : 1663-4446

Éditeur

Librairie Droz

Édition imprimée

Date de publication : 15 octobre 2011

Pagination : 135-155

ISBN : 978-2-600-01551-6

ISSN : 0048-8046

\section{Référence électronique}

Mohamed Cherkaoui, «Some Generative Mechanisms of Intellectual Production », Revue européenne des sciences sociales [En ligne], 49-1 | 2011, mis en ligne le 01 janvier 2015, consulté le 01 mai 2019. URL : http://journals.openedition.org/ress/873 ; DOI : 10.4000/ress.873 


\title{
SOME GENERATIVE MECHANISMS OF INTELLECTUAL PRODUCTION
}

\author{
THE THREE MARKETS THEORY
}

MOHAMED CHERKAOUI

CNRS / Université de Paris-Sorbonne mcherkaoui@yahoo.fr

\begin{abstract}
In this contribution, the author tests empirically the three markets' hypothesis developed by Ben-David and Boudon on the basis of data on intellectual production in the field of social sciences and humanities in Morocco. The article highlights the mathematical models of the intellectual production that are found to be different from those that characterize production in the natural sciences. One important conclusion the author comes up with in his study is that «Matthew effect», identified by Merton for the natural sciences, is nonexistent in the social sciences and humanities. Production in these latter disciplines does not fit in this effect according to which the act of publishing once increases the probability of publishing a second time and so on. Such an absence of cumulative process is accounted for based on the structure of market supply and demand of intellectual products as well as the increasingly tenuous role played by the scientific community.
\end{abstract}

Keywords: scientific production; market's structure; "Mathew" effect; scientific community; mathematical model

Résumé. Cet article entend mettre à l'épreuve l'hypothèse des trois marchés élaborée par Ben-David et Boudon en la soumettant aux caractéristiques de la production intellectuelle en sciences sociales et humaines au Maroc. À l'appui de données longitudinales qui s'étendent sur cinq décennies, l'auteur fait alors état de modèles mathématiques en sciences humaines et sociales différents de ceux qui caractérisent la production dans les sciences de la nature où la propension à publier un article scientifique croît de manière cumulative à raison du nombre d'articles publiés. L'une des conclusions importantes que l'auteur en déduit est que « l'effet Mathieu », identifié par Merton pour les sciences de la nature, est inexistant dans les sciences sociales et humaines. Selon l'auteur, l'explication de l'absence de ce processus cumulatif se fonde sur la structure des marchés de l'offre et de la demande des produits intellectuels et sur le rôle de plus en plus ténu que joue la communauté scientifique en sciences humaines et sociales.

Mots-clés: production scientifique; structure de marché; effet «Mathew»; communauté scientifique; modèle mathématique 
This contribution presents partial results of one of the research studies I have been conducting on Moroccan universities. As these studies have been developed in the framework of a research contract, they follow the rules for that type of work, namely collecting data and presenting analysis that will be useful in answering certain questions raised by the public authorities - or questions they are supposed to raise, in any case. But they also have a strong theoretical objective: they are an integral part of a preexisting research program, with its hard core and its scientific activity, part of which has already been mapped out while another part is open-ended, aiming at accumulating knowledge and discovering new phenomena.

One of these studies bears on the intellectual production of academics and non-academics. On the basis of the data collected, I have tested certain hypotheses about the mechanisms that generate intellectual production in a particular social environment. However, it seems to me that the results could be readily extended to other countries. One of the virtues of the study is that it identifies the effects of a combined absence: not having a public research policy and not having an international research evaluation body. As we shall see, this state of affairs has brought about an acute crisis in intellectual production.

The corpus I constructed encompasses all intellectual production in the social sciences and humanities from 1960 to 2006. It includes literary works published by Moroccans. I have counted up all materials written in all languages used by Moroccan authors regardless of place of publication. The data base comprises 57000 references: 30000 articles, I3 000 books and I4 000 other documents (chapters or essays in collective works). Here I will only be presenting the results of bibliometric data analyses related to the general hypothesis. For more information on the corpus and other extensively treated themes, the reader is invited to refer to Cherkaoui (2011). 


\section{“SECULAR” MARKET AND “REGULAR” MARKET}

My point of departure is Ben David (1975) (1979) (1980) and Boudon's (1986) hypothesis, which, to my knowledge, has never been empirically tested and enriched. According to them, intellectual production in the social sciences and humanities is arbitrated by the various readerships, of which there are a total of three: the scientific community; social groups, whether institutionalized or not (the state bureaucracy, political parties, unions, employers, etc.); public opinion at large or any citizen interested in a social issue such as, women's movements, youth, students, migrants. Researchers working in the humanities and social sciences may be more or less sensitive to the structure and fragmentation of the markets they write for; they are more or less informed about the nature and structure of demand from these markets.

A historian may feel that a book on a dynasty would dovetail with the public's curiosity. If he gives precedence to the community of scholars, he will handle his subject in accordance with science-of-history norms and he will be relatively unconcerned about how his work is received by the larger public. But he may also grant more importance to this potential, wider readership and therefore present his work in a form that would be more acceptable to them, without taking into account the community of historians.

The first market is the scientific community, made up of the author's peers. Here, production assessment rules are known to and accepted by all members of the group. The symbolic gratification that remunerates the researcher is entirely in the hands of his colleagues in the same discipline. The symbolic resources (distinctions) or material ones (promotion, appointment to a university job) involved are granted by organizations that emanate from the academic peer community.

The second market is made up of informed readers. This market can readily be qualified as "secular" by opposition to the first, the "regular", who are subject to strictly scientific rules. It involves different evaluation and remuneration mechanisms than for the first type of market. My fundamental hypothesis is that Moroccan social sciences and humanities scholars' production corresponds to this second type. Moroccan academics attribute greater importance 
to the second market than the first because neither their careers nor their research funding depends on the volume and the quality of their production.

In the third type of market, the public at large is the supreme judge. This is the case for literary production, i.e., novels and other intellectual productions. I would recall that this third market is drastically limited in a country of endemic illiteracy where even the so-called "learned" seldom read.

\section{PRODUCTION AND PRODUCTION MODELS}

Many studies have shown that in several scientific disciplines, primarily in the so-called exact sciences, scholarly production follows mathematical laws. These laws refer firstly to the skewness of production distribution, reflecting strong inequality among individuals: the curve is heavily concentrated on the left, with a long tail on the right; secondly, to the persistence of this asymmetry over time; thirdly, to the fact that inequality within generations and cohorts increases. This is a central concern for the economy and sociology of science. Few European studies allow for testing these three "laws" or, to put it more humbly, these three empirical regularities. To my knowledge, there has been no bibliometric study of developing countries that has identified them, or confirmed or invalidated their relevance for such countries. The present study is surely the first of its kind.

Lotka's (1926) and Price's (1963) laws, based on the distribution of individuals' publication of articles in scientific journals, show that researchers' production has a strongly asymmetric right-hand distribution. "Lotka's law" derives from American data on publishing in the field of chemistry from 1907 to 1916 and physics over the entire pre-1900 period. It is formulated as follows: if $y x$ is the frequency of researchers publishing $x$ articles, then $x n y x=c$, where c depends on $n$, and $n$ is estimated from the coefficient of the absolute value of the right-hand slope, which fits the relation between the logarithm of the frequency of researchers who have published I, 2, 3, ... articles (y-axis) and the number-of-articles logarithm (x-axis). Lotka established that the $n$ parameter is constantly between I and 2. For his researcher samples, he found that $\mathrm{n}$ was 
approximately equal to 2. It will be noted that the number of articles $x$ was never nil in his study because he was using data on researcher publications; he therefore had no information on absence of publications. To find the value of c, Lotka suggested adding the $y x$ frequencies found for each value of $\mathrm{x}$ in the interval $[\mathrm{I},+\infty]$. This gives:

$$
C=1 /\left(\sum_{x=1}^{\infty}\left(1 / x^{n}\right)\right)
$$

Lotka's law generates skewed distributions with very long upper tails to the right with a single one-publication mode: the upper $10 \%$ of authors - i.e. the most prolific authors - are responsible for $50 \%$ of total output in a given research field over a given period (Allison P. D., Price D. J. D. et al. 1976). This last result is now called "Lotka's law" given that it turned out to be an empirical regularity.

But as Herbert Simon (1957) showed in a brief yet dense article, several sociological, economic and biological phenomena follow the same class of skewed distribution functions, all of which share the same characteristics. Those phenomena include distribution of words in prose samples by frequency of occurrence, distribution of scientists by number of papers published, distribution of cities by population, distribution of incomes by size, and lastly, distribution of biological genera by number of species.

Distributions of these empirical phenomena are all J-shaped, or at least highly skewed with very long upper tails. They can be described by the general function:

$$
f(i)=\left(\frac{a}{i^{k}}\right) b^{i}
$$

where $a, b$, and $\mathrm{k}$ are constants and $\mathrm{b}$ is close to unity.

This property is characteristic of contagious processes such as the negative binomial law or Fisher's logarithmic series, which I will briefly discuss further on. I will also test how well these laws fit my data. 
The second property is that the value of the k exponent is over I in the case of word occurrence frequency and close to 2 for urban populations. The third property is that for scholarly production (among other entities), the function describes not only curve tail but overall distribution for low i values.

Herbert Simon showed that what leads to these distribution sets, which perfectly describe data on researcher production, are stochastic processes similar to those that generate the negative binomial law or logarithmic series. In our case, the stochastic process operates as follows: the author of an article to be published in a scholarly journal is selected using a sample stratified into authors who have already published I, 2, ... articles; the probability of each stratum is proportional to if(i). Probabilities for each author need not be proportional to i; only aggregate probabilities for authors have to be. This means that an author's probability of being selected will be higher if he recently published something than if he has not published anything.

\section{PRODUCTION DISTRIBUTIONS BY NUMBER OF UNITS PRODUCED}

Here I will be identifying the laws characteristic of production in the humanities and social sciences, while testing the relevance of the laws discovered for the so-called exact sciences. Since the data base is longitudinal and covers nearly five decades, it will be easy to study variations over time. Suffer me to repeat that this constitutes the only empirical research study in this field. However, the conclusions I draw from it are quite plausibly extendable to production in other countries. 
Figure [I]: Distributions of overall production by academics by type of document for the period 1960-2006.

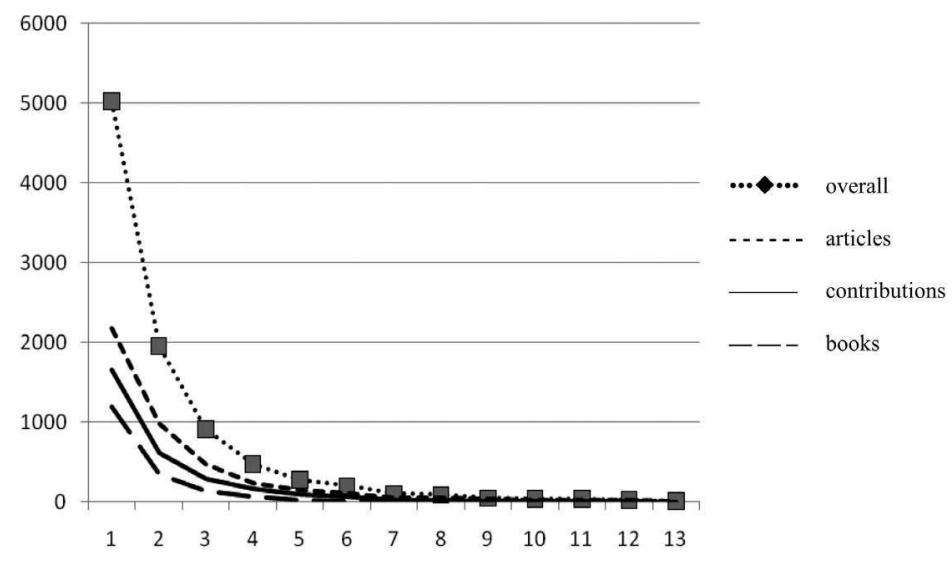

These curves represent overall academic production distributions from I960 to 2006 for all types of documents and by each of the three types. By academics' or scholars' production I mean university professors' publications. The $\mathrm{x}$-axis is for number of documents published. I limited it to Iz. The y-axis is for number of academic researchers who have produced between I and I3 documents. The number of scholars who published more than iz documents is so low that it need not be taken into account here. Furthermore, as is shown graphically, production volume quickly moves toward a limit approaching zero.

A few preliminary remarks are necessary here. Overall distributions and distributions by document type have practically the same shape, whether we are looking at articles, chapters or essays in collective works (hereafter referred to as "chapters") or books. They are highly skewed to the right and turn upward. They are convex, meaning that when the number of units produced increases, production decreases. All production curve slopes are negative. One property of the models I will be fitting to the observed data is that the curves representing them have a second derivative equal to zero. 
This is the case regardless of period considered: the curve representing the trend for each of these types of product is virtually the same for all corpus data. This result was expected. We were not expecting production to be either egalitarian or homogeneous. It has no chance of following the Laplace-Gauss law. This reflects what Lotka identified in the I920s and what many sociologists of science have continued to confirm; it therefore seems fair to say that the concentration of production in the "hands" of certain producers is a universal phenomenon. There is no reason for Morocco to be an exception to this rule.

In fact, several models can reasonably claim to describe the nature of the phenomena studied. I cannot cite them all, but will just mention those used most often, for reasons related to the goodness of fit and to how readily they can be justified on the basis of statistical theory. I am referring to the inverse model, Fisher's logarithmic series, the negative exponential, the negative binomial law, Poisson's binomial with contagious processes, geometric and Zipf laws, and lastly the power model, a particular case of beta distribution, as shown by Johnson and Kotz (1970). The shape of all these laws is congruent to my empirical data.

Older studies by Williams (1945) and Riddel (1945) showed that publications by scholars sometimes followed either the geometric law or Fisher's logarithmic series, as Leclerc (1970) recalls, though without providing a procedure for estimating the parameters of this last law.

While each of these laws reflects the hypotheses on which it was constructed, it is necessary to explain why we choose one model rather than another. Have we got empirical or theoretical arguments for choosing one or the other? We can begin by asking about degree of congruence to the data. This is of course one of my selection criteria, since the first objective of my work is to precisely describe empirical data before looking into the mechanisms that generate them. 


\section{GENERAL PRODUCTION DISTRIBUTIONS BY NUMBER OF UNITS PRODUCED}

As recalled above, there are many models that might describe data on intellectual production as correctly as possible. In addition to Poisson's model and the negative binomial law, those that best fit the data are simplified hyperbolic or inverse regression, negative exponential, and power function models. The estimated parameter values for each of the three models are

$$
\begin{aligned}
& \mathrm{Y} 1=-724.223+5600.003 / \mathrm{X} \\
& \mathrm{Y} 2=4948.346 * \exp (-0.510 \mathrm{X}) \\
& \mathrm{Y} 3=7354
\end{aligned}
$$

$x$ being number of documents.

Figure [2]: Overall production distribution for academics, 1960-2006, and goodness-0f-fit of the inverse, negative exponential and power function models

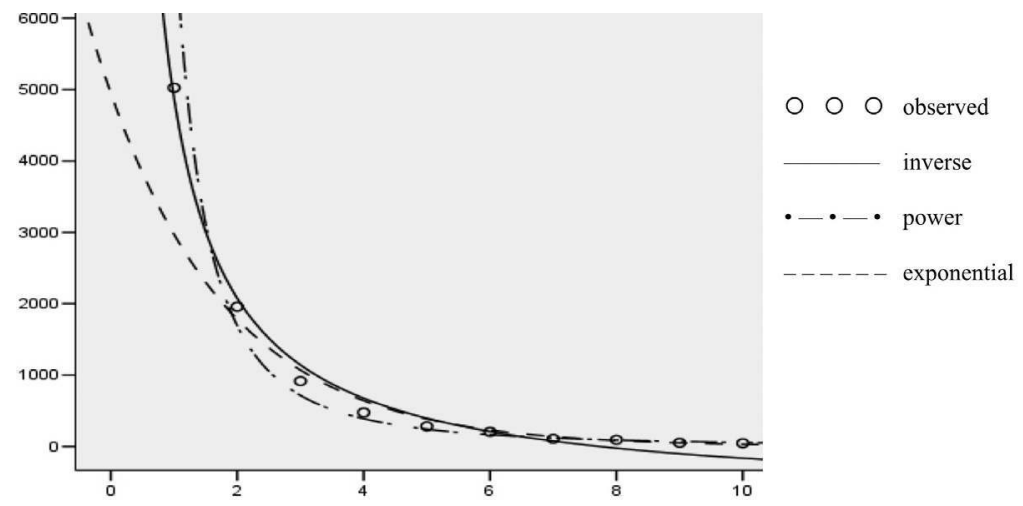

$\mathrm{R}^{2}$ values for the three models are equal, respectively, to 0.99, 0.97 and 0.978 .

We obtain the same results for type of document. To avoid overloading the presentation here, I will not present the models' estimated parameter values. 
How valid is the fit of these models, first to total production for each of the five-year periods, then to production by document type? From here on I will limit my investigations to the five post-197 I five-year periods, because the numbers of scholars participating in intellectual production in the preceding period were very low.

In fact, it is important not to forget that the oldest scholars are also those who produce the most. We have been expecting that distribution is more skewed to the right for the years 2002-2006 than for the earlier five-year periods because the authors here were often the same professors at different moments in time. Table [I] presents the estimated parameter values of these models for the five-year periods

Table [I]: Modeling of production by 5-year period

\begin{tabular}{|c|l|c|}
\hline FIVE-YEAR PERIODS & \multicolumn{1}{|c|}{ MODELS } & $R^{2}$ \\
\hline $1972-1976$ & $Y=-6,908+48,65 \mid / X$ & 0.984 \\
\hline $1982-1986$ & $Y=-66,998+479,684 / X$ & 0.958 \\
\hline $1982-1986$ & $Y=529,496+\exp (-0,633 X)$ & 0.926 \\
\hline $1992-1996$ & $Y=-136,822+1075,538 / X$ & 0.99 \\
\hline $1992-1996$ & $Y=892,726+\exp (-0,49 X)$ & 0.947 \\
\hline $2002-2006$ & $Y=-190,237+148 \mid, 876 / X$ & 0.99 \\
\hline $2002-2006$ & $Y=1348,345+\exp (-0,515 X)$ & 0.97 \\
\hline
\end{tabular}

\section{ANALYSES OF PRODUCTION DISTRIBUTION BY DOCUMENT TYPE AND 5-YEAR PERIOD}

I will proceed in the same way for each type of document; that is, articles, books, and chapters for the different 5 -year periods. So as not to weigh down the presentation, I have limited myself to the essential, pointing out most importantly that data analysis results all indicate the general validity of the previously established propositions. They are valid for all types of intellectual production by Moroccan scholars. 
Academics production distribution by document type is quite similar to the overall distribution of Figure [I] and requires no further commentary. It clearly shows that

1. Production distributions by document type are similar, and akin to the overall production distribution analyzed previously. Moreover, they are described by the same inverse, exponential, and power models.

2. These distributions differ primarily by curvature, as reflected by the coefficient value $B 1$. We see that that value diminishes when we move from articles to chapters to books. The most curious feature is that the difference or the ratio between $\beta 1$ values for each pair of document types is practically the same: equal to 0.75 . If we think of the $B 1$ parameter as designating production rate, then the article production rate is $25 \%$ higher than the chapter production rate and $50 \%$ higher than the one for books.

3. The means for article, chapter, and book production are respectively 2.29, 2.11 and 1.71 . It is hardly surprising to observe that scholars produce more articles or chapters than books, which demand a greater time-investment. The reader will have understood that this calculation concerns only scholars who produce. To get a precise idea of the distribution, the reader has to know that from 1960 to 2006, 54.4\% of them published one document; 21.2\% published two; $9.9 \%$ published three, $5.1 \%$, four; $3 \%$, five, etc. - all in all, a remarkably poor performance.

4. Standard-deviations for the distributions of articles, chapters, and books are respectively 6.26, 6.4 and 6.33. This means that production inequalities among scholars who actually did publish at least one document in the five decades are similar, regardless of type of document produced.

We can also note that the deviations from the mean are of practically equal value (they differ by a few tenths of a point). The highest standard-deviation (6.6), corresponding to chapter distribution for 1982-1986, differs from the lowest (6.3), for book distribution for each of the five-year periods, by only three-tenths of a point. This result suggests that production inequality does not increase over time but is nearly stable. 
We can now ask if production distributions by five-year period change by document type. Here I have limited myself to the example of article distribution since the ones for books and chapters are identical to it.

Figure [3]: Academic production distributions by document type and five-year period (articles)

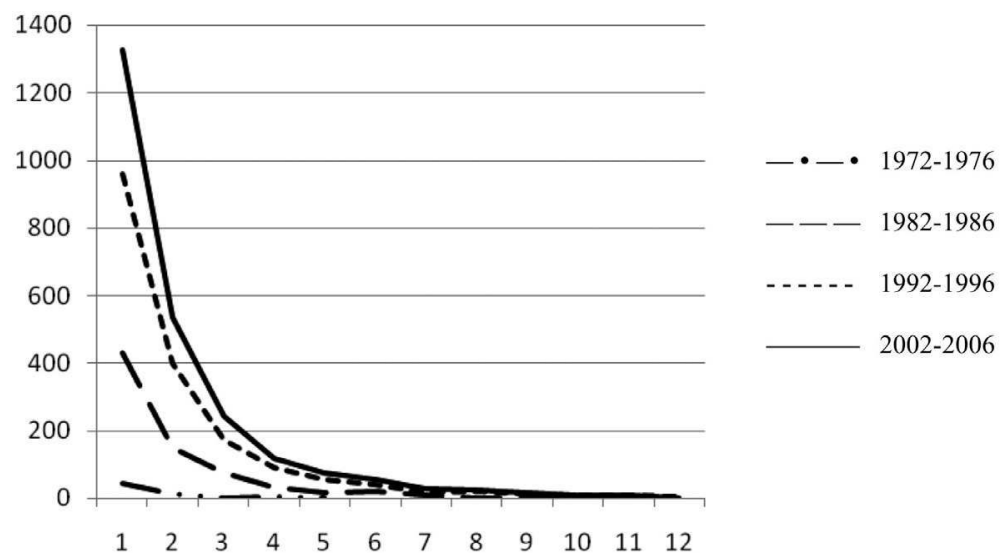

Analysis of these distribution data lead to the following conclusions:

1. Production means are practically stable over time. However, they change by type of document, fluctuating around 2.20 productions for articles, 2.10 for chapters and 1.70 for books. The reader will have noted that these values are also equal to the means for each document type independently of time.

2. Variances are of almost equal value regardless of five-year period. This means that production inequalities among scholars are stable over time.

3. The inverse (or power function) model best fits all the data for all the periods considered.

4. The value of this model's $B 1$ coefficient tends to increase with time for all types of document.

It is important to ponder the result for stability of inequalities over time. This result goes against many European and American studies concluding that inequality increases. Why do the Moroccan data falsify the "Matthew effect" identified by Merton (1968), according to which having published once 
increases the probability of publishing a second time, and so on? It will be recalled that Merton was referring to the passage in the New Testament where Christ says: "For whosoever hath, to him shall be given, and he shall have more abundance: but whosoever hath not, from him shall be taken away even that he hath." (Matthew I3:I2). Why doesn't the mechanism governing intellectual production in Morocco contain a positive or negative retroactive effect that would bolster or inhibit production?

To check the validity of these propositions, I submitted the empirical data to more detailed examinations, namely by fitting the geometric law, Pascal's law, Fisher's logarithmic series, Poisson's law with contagious processes - more generally the skew distribution functions class formalized by Herbert Simon. Studies have shown that scholarly production follows the negative binomial law or Poisson's law with contagious process. This process signifies that having published a document increases the probability of publishing a second, third, etc. My calculations clearly show that the data are not at all congruent with Poisson's law with contagious processes and that the Matthew effect is totally absent from production in social sciences and the humanities.

Let me recall that sociologists and economists of science assume the existence of a cumulative advantages mechanism in research that reflects a dynamic individual trajectory, a trajectory in which success generates more success. Their interpretation (e.g., Allison, Long and Krauze, 1982) may be summed up as follows: scientists whose first publications at the start of their career are successful have an easier time obtaining such resources as public and private funding, time to do research, laboratories, and talented students. These advantageous conditions make new research possible. These scholars are encouraged by their colleagues to continue investing time and energy in research. Everything works together to make them more productive over their career or at least to maintain their productivity at a high level. But researchers who have not begun their career well run the risk of ceasing all research activity due to the accumulation of obstacles. 
My two-fold hypothesis for explaining the fact that there is no retroactive effect in production is as follows: because the Moroccan state invests no financial resources that would stimulate research in the social sciences and humanities, and because promotion within universities is not at all dependent on publishing, academics are not encouraged to produce. And if by chance they do produce, this is primarily for reasons that have nothing to do with public policy or pressure from the local scientific community, since, as explained, both are non-existent (see Cherkaoui 2009).

The new university reform under way in Morocco provides for setting up evaluation committees that will use research and publications as criteria for promotion, together with teaching and activities in the collective interest. But we don't have to be Cassandra to predict that such a reform will at best have no effect and at worst be counterproductive: many scholars will follow the letter rather than the spirit of the reform, turning it into a "mock bureaucratic" rule by publishing anything they can in any kind of medium. Without the institution of a national evaluation body supported and in part legitimated by international experts, as is the case in the majority of countries, the reform will not produce the expected results.

\section{ANALYSES OF NON-ACADEMICS PRODUCTION DISTRIBUTION BY DOCUMENT TYPE AND FIVE-YEAR PERIOD}

A comparison between academics' and non-academics' productions will provide another means - quite original, if indirect - of testing the general theory of the three competitive markets. To my knowledge, no study in any country has taken up this problem or tried to develop parallels between these two populations. The fact is that non-academics do sometimes publish scientific and technical documents, and they are even more likely to publish intellectual ones. It would be a pity not to see what we can learn from studying their production. 
Can the previously established propositions on academics be applied generally or are they, on the contrary, specific to the teaching body? If no difference is found between the two producer groups, how can we explain that fact, given that we normally expect academics to produce much more than non-academics? To answer this question, I have performed exactly the same analyses on non-academics' production as the ones done on academics' production. I begin by studying overall production distributions and distributions by document type for the 1960-2006 period; I then analyze non-academics' production distributions by type of document and five-year period.

Figure [4]: Non-academic production distributions by document type from 1960-2006.

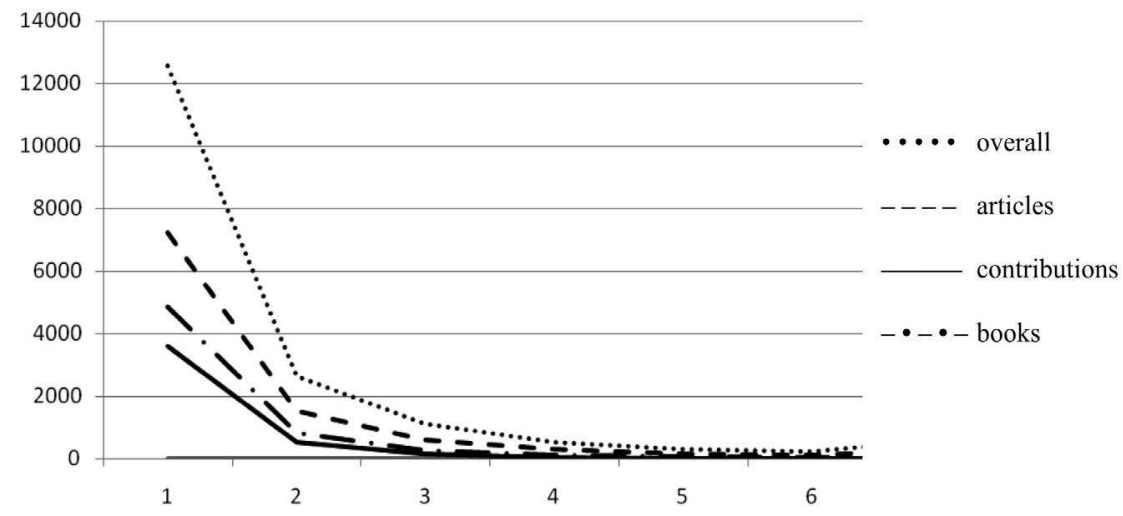

The general shape of these curves is very similar to the ones obtained for academics. Better yet, the three models that best fit the data for non-academics are the inverse, exponential and power models - the same ones that applied for the empirical data on academics. The only differences observed lie in the estimated parameter values. 
The estimated parameter values for each of the three models are:

$$
\begin{aligned}
& \mathrm{Y} 1=-2762.529+14355.864 / \mathrm{X}[6] \\
& \mathrm{Y} 2=8759.11 * \exp (-0.555 \mathrm{X}) \\
& \mathrm{Y} 3=10107.338 *\left(\mathrm{X}^{* *}-1.941\right)
\end{aligned}
$$

A quick perusal of the theoretical data generated by the three models shows that despite an apparently better fit for the inverse model, the exponential model is more realistic, since it does not generate negative theoretical values, while the power model actually describes the data even better than the exponential model.

Table [2]: Observed data (OD) and theoretical data generated by the inverse model (IM), the exponential model (EM) and the power model (PM) by number of documents per author (NDA)

\begin{tabular}{|c|c|c|c|c|}
\hline NDA & OD & IM & EM & MP \\
\hline 1 & 12559 & 11593 & 5028,08 & 10107,34 \\
\hline 2 & 2612 & 4415,40 & 2886,32 & 2633,083 \\
\hline 3 & 1096 & 2022,76 & 1656,86 & 1198,80 \\
\hline 4 & 528 & 826,44 & 951,11 & 685,95 \\
\hline 5 & 300 & 108,64 & 545,97 & 444,87 \\
\hline 6 & 215 & $-369,89$ & 313,41 & 312,3 \\
\hline 7 & 575 & $-711,69$ & 179,91 & 231,56 \\
\hline
\end{tabular}

Will we obtain the same results if we take document type into account? The answer is yes. In general, the power model fits the non-academic production data best for all document types.

We can now examine the production distributions by five-year period and document type. Figure [5] presents the results for all types and for books only, since those for articles and other contributions are identical to those results. 
Figure [5]: Non-academic production distributions by all documents and by document type and five-year period

All types together:

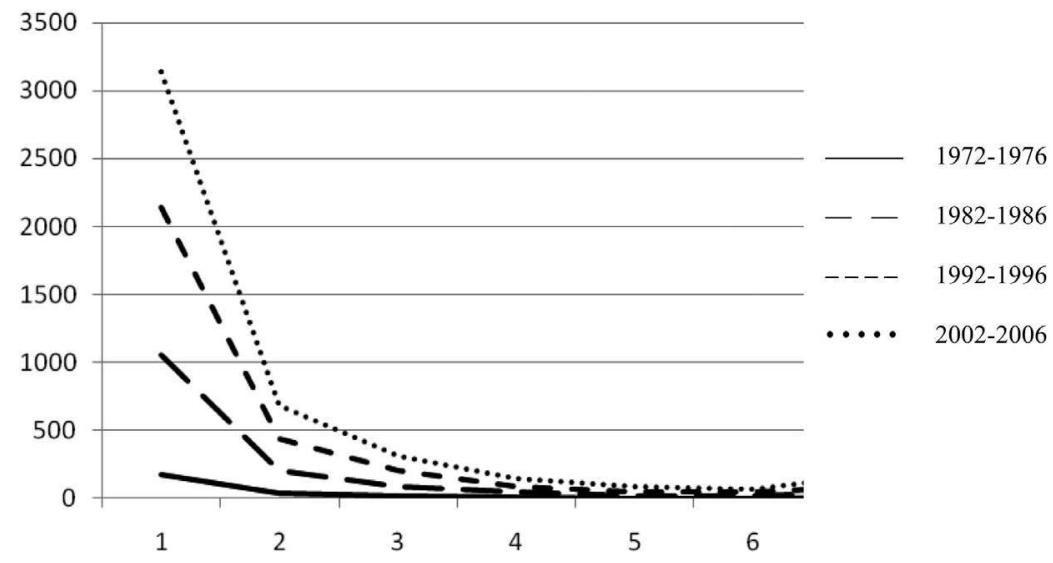

Books:

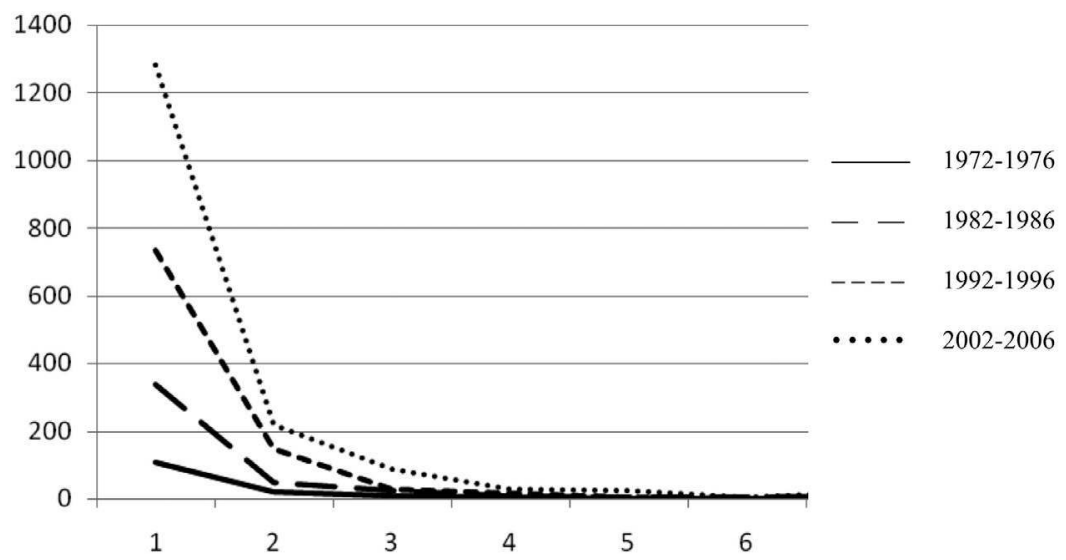


Table [3]: Mean, variance and standard-deviation of overall production distributions by fiveyear period (non-academics)

\begin{tabular}{|c|c|c|c|c|c|c|c|c|c|}
\hline & OVERALL & $1967-71$ & $1972-76$ & $1977-81$ & $1982-86$ & $1987-91$ & $1992-96$ & $1997-01$ & $2002-06$ \\
\hline MEAN & 1.68 & 1.47 & 1.67 & 1.47 & 1.64 & 1.64 & 1.64 & 1.71 & 1.76 \\
\hline $\begin{array}{c}\text { STANDARD- } \\
\text { TYPE }\end{array}$ & 3.34 & 3.34 & 3.32 & 3.48 & 3.34 & 3.34 & 3.33 & 3.28 & 3.25 \\
\hline
\end{tabular}

From analysis of the curves and different elementary statistics such as mean and standard-deviation - which inform us about degree of inequality, since standard-deviation is proportional to the Gini index - we can make the following deductions:

1. Production means are practically stable over time, as shown by Table [3] data. They do vary by type of document, however. For articles, they fluctuate around 1.68 productions; 1.30 for chapters; 1.39 for books. It is hardly surprising that non-academics' production is lower than that of the academic body for all types of document. Academics produce 1.3 times more articles, 1.61 times more chapters, and 1.22 times more books than non-academics.

2. As was the case for academics, the standard-deviations are of almost equal value regardless of five-year period. This means that production inequalities among non-academics are stable over time. The standard-deviations fluctuate around 3.35 for articles, 3.36 for chapters, and 3.54 for books. The reason we see no increase or decrease in production inequality for non-academics is that there is no mechanism to strengthen or weaken inequalities - specifically, demand has not changed since the early 1960s.

3. The model that best fits the data as a whole and for all periods considered is the power model.

It seems to me that the reason there is no difference in kind between academics' and non-academics' production is that the same market mechanisms are at work in both cases: both academic and non-academic publication supply is addressed to the same market, that of informed readers. Contrary to scientific production in the United States and Europe, aimed primarily at the relevant scientific communities, Moroccan production in the humanities and 
social sciences is addressed to the readership I have called "secular". Some Moroccan researchers do produce for a scientific community, of course, but there are so few of them that they do not influence the overall result.

I will conclude by recalling that I have here made use of only part of the empirical material and analyses that constitute the vast research project I have been conducting, and whose results will lead to a more substantial publication. Let me also conclude by recalling two findings.

I. For the most part, the three-market theory has been confirmed.

In the absence of a strong scientific community, humanities and social science researchers turn toward the "secular" market to obtain material and symbolic gratifications. The few academics who do produce give more importance to the second market than the first. This is understandable: their careers can hardly be said to depend on the volume and the quality of what they produce; their best hope is to profit from getting some visibility for their publications in the mediating organizations of the second market.

We do not have to be seers to interpret this fact as foretelling the decline and death of this embryonic scientific community. If academics, but above all the public authorities, do not get a better grasp of the situation, if they don't invest the resources necessary first to save, then to stimulate scientific production, and to refound the University in Humboldt's sense of the term, then the Moroccan university will be a thing of the past.

A further proof of this is provided by the entirely original comparison between academic and non-academic production levels. This shows that, contrary to all expectations, the same market mechanisms are at work for both: academics and non-academics address their publications to the same market. 
2. The positive but above all the negative effects of public policy on intellectual production in particular and the university in general have been demonstrated.

We cannot let academics off the hook, of course; they are partially responsible for the present production crisis, since most of them have never published a line in their lives. But the state has greater responsibility than academics for the anomic situation of scientific production.

The absence of the Matthew effect characteristic of intellectual production is due to the facts that the state invests no financial resources to stimulate social sciences and humanities research and that promotion within universities does not at all depend on scholars' publications. Still more: I demonstrated in Cherkaoui (20II) that the orientation towards the "secular market" has a negative effect in the emergence of a scientific community and allows the intrusion of non scientific criteria in our disciplines.

\section{BIBLIOGRAPHY}

ALLISON P. D., LONG, J. S. and KRAUZE, T. K., 1982, "Cumulative Advantage and Inequality in Science", American Sociological Review, 47(5), p. 615-625.

-, PRICE D. J. D., et al., 1976, "Lotka's Law. Problem in its Interpretation and Application" Social Studies of Science, 6 (2), p. 269-276.

BEN-DAVID J., 1975, "Innovations and their Recognition in Social Science", History of Political Economy, 7, 4, p; 434-455, repris in Ben-David, I991.

-, 1979, "The Ethical Responsibility of Social Sciences", in Segerstedt (ed.), 1979.

-, 1980, "Sociology and its Uses", Schweizerische Zeitschrift für Soziologie, 6, 3, p. 335-352.

-, 1991, Scientific Growth. Essays on the Social Organization and Ethos of Science, Berkley, University of California Press.

BOUDON R., 1986, "L'intellectuel et ses publics: les singularités françaises" in Reynaud and Grafmeyer (eds), 1986, Français, qui êtes-vous? Des essais et des chiffres, Paris, La Documentation française. 
CHERKAOUI M., 2009, "The Three Markets Theory and Some Unintended Consequences of Public Policies", in Cherkaoui and Hamilton (eds), 2009.

- and HAMILTON P. (eds), 2009, Raymond Boudon, A Life in Sociology, Oxford, Bardwell Press.

-, 20।I, Crise de l'Université. Le nouvel esprit académique et la sécularisation de la production intellectuelle, Genève, Droz.

JOHNSON N. and KOTZ S., 1970, Distributions in Statistics, 4 vols, New York, Houghton Mifflin Co.

LECLERC B., 1970, Distributions statistiques et lois de probabilité, Paris, Mouton.

LOTKA A. J., 1926, "The Frequency distribution of scientific productivity", Journal of Washington Academy of Science, 15, p. 317-323.

MERTON R. K., 1973 (1968), "The Mattew Effect in Science", in Merton R.K., The Sociology of Science. Theoretical and Empirical Investigations, Chicago, University of Chicago Press.

PRICE D. J. D., 1963, Little Science, Big Science, New York, Columbia University Press.

RIDDEL W. B. J., 1945, "The Relation Between the Number of Speakers and the Number of Contributions to the Trans. Ophtalim. Society of U.K. Between 188I and 1889", Annals of Eugenics, 12, p.274-279.

SEGERSTEDT T. (ed.), 1979, Ethics for Science Policy, Oxford, Pergamon Press.

SIMON H., 1957, "On a Class of Skew Distribution Functions", in Simon H., Models of Man, New York, John Wiley and Sons.

WILLIAMS C. B., 1945, "The Number of Publications Written by Biologists", Annals of Eugenics, 12, p. 143-146. 
